\title{
Water Pumping System using Solar and Wind Power
}

\author{
Srikanth $\mathrm{D}^{1}$ \\ Assistant Professor, \\ Department of Electrical and Electronics Engineering, \\ Vignan Institute of Technology and Science, \\ Telangana.
}

\begin{abstract}
This paper gives a transparent idea to beat the matter of water pumping during power cuts by using the windmill and photovoltaic cells for the assembly of electricity for the water pumping system. Aero turbines convert wind energy into rotary energy. Photovoltaic cells convert alternative energy into electrical energy. A mechanical interface, consisting of a step-up gear, and an appropriate coupling transmits the energy to an electrical generator and also consisting of a reciprocating pump for pumping water from the underground level. In our project, both the assembly of electricity and therefore, the pumping of water may be easily done. As gear is connected to the pinion which increases the speed because the dynamo rotates, power is produced, and therefore, the main shaft is connected to the pump which pulls water from the bottom level. The energy from the sun is collected by the solar panel and is converted into DC and then is inverted into AC. The mains theme of this project is the way to use renewable energy effectively by keeping the environment as clean as possible.
\end{abstract}

Keywords-Solar Panel; Wind Turbine; Comparator; Step-up Transformer; Inverter.

\section{INTRODUCTION}

A pump operates on mutual motion -- up and down pushing and actuation on a piston which attracts water up out Pumping water was one among the firsts, and vital most essential uses for windmills and mistreatment the energy for turning a millstone to grind grain is additionally essential and also the star plate that's mounted around the wind turbines creates a current within the type of DC current and transfer it to converter. A converter is a device that changes 'Direct current (DC)' to 'Alternating current (AC)'. Inverter offer this to the battery and also the DC motor via transmission lines. The DC motor converts the current into the mechanical (rotational) energy and provides it to the foremost shaft that's connected to the crank mechanism. Presently windmills are principally used for the generation of electricity, grinding grain or pumping water. There's one in a very park simply south of the University of Illinois here that pumps water of the well. Additionally, there is a unidirectional valve to remain the water from flowing back to the well once the pump makes a coming stroke. A windmill generates motility by turning a shaft. The speed of the turning could also be adjusted by mistreatment gears of varied sizes. To point out the motility of a shaft into mutual motion, a slider-crank mechanism is used. A link is a connected perpendicular to the shaft, and another rod is connected vertically from the sting of the wheel to the pump down below. As a result of the center of the wheel does, "t move, however, the sting goes spherical and spherical, the

\author{
K. Himaja ${ }^{2}$, Ch. Swasthik ${ }^{3}$, P. Uday Kumar ${ }^{4}$ \\ U.G. Student, \\ Department of Electrical and Electronics Engineering, \\ Vignan Institute of Technology and Science, \\ Telangana.
}

rod is visiting be a force up. These days, you will be able to generate electricity with a windmill and star plate and connect that to an electrical pump. Now-a-days, solar energy is additionally ordinarily employed in most the fields to urge power. Starr water pumping system is one among the reliable and also the renewable declares pumping water to the agriculture lands. The value of the water pumped up by physical phenomenon systems is additionally plenty of but that of water pumped up mistreatment standard gridconnected.

\section{A. Overview}

In this project, we try to design and operate a water pumping system using a turbine and also solar cells. The alternative energy is gained by the solar battery and converts that voltage into energy which causes to rotate the shaft. The wind energy gained by the turbine is converted into energy. The target of this project is to style wind and solar operated water pumping system that's capable of pumping water in planet situations.

\section{BLOCK DIAGRAM}

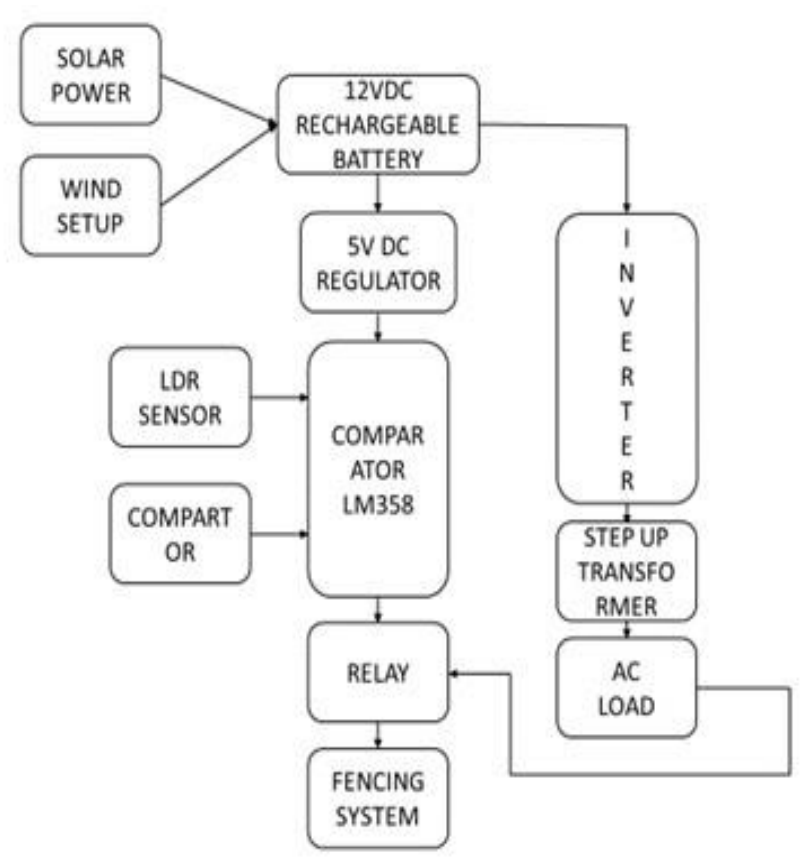

III. HARWARE DESCRIPTION

The main required components for the system are-

- Solar Panel

- Wind Turbine 
- Rechargeable Battery

- Voltage Regulator

- LM358 Comparator

- Inverter

- Transformer

- Relay

- LDR Sensor

Solar panel:

Solar panel is a device which converts the light energy into electrical energy. When light is allowed to fall on this it generates a voltage across its terminals. The voltage increases with increase in intensity of light.

\section{Wind Turbine:}

Wind turbine is an electrical device that can effectively convert wind energy into electrical power. Wind preliminary hits the turbine blades, causing them to rotate and switch the rotatory engine linked to them which modifies the mechanical energy to motility power, by means of shifting a shaft that is linked to a generator.

\section{Rechargeable Battery:}

A rechargeable battery or a storage battery is a type of electrical battery that can be charged, discharged into a load, and recharged as many times, which is contrary to a normal disposeable battery, which is supplied fully charged and cannot be recharged again.

\section{Voltage Regulator:}

Voltage regulator is an electronic device which maintains a fixed dc output voltage even if there is any change in supply voltage or any load variations. The ac ripple voltage which are not removed by filter can also be eliminated by the voltage regulator.

\section{LM358 Comparator:}

The LM358 is a low power dual operational amplifier integrated circuit. It is used in detector circuits. The abbreviation LM358 indicates an 8-pin integrated circuit, comprising two operational amplifiers at low power.

Inverter:

An inverter is a device which is mainly used to convert the $\mathrm{DC}$ i.e., direct current into AC i.e., alternating current electricity. The output of an inverter can either be single phase or three phase. Besides changing the $\mathrm{DC}$ into $\mathrm{AC}$, the inverter also keeps a constant voltage on the AC side.

\section{Transformer:}

A transformer is a static device which transmits electrical voltage from one circuit to another circuit by using the principle of electro magnetic induction. An electrical device which increase the voltage from primary windings to the secondary windings is knowns as step up transformer. In the proposed system we use a step-up transformer.

Relay:

A relay is an electrical device. It is generally operated as a switch. The main function of relay is open or close the circuits. It opens the circuit when there occurs a fault.

\section{LDR Sensor:}

Light dependent resistors which are also known as Photo resistors, are devices that are sensitive to light that are mainly used to indicate the presence or absence of light, or to measure the light intensity. During the dark, the resistance is very high and sometimes very high which is nearer to $1 \mathrm{MO}$, but when it is exposed to the light, the resistance drops very sharply, sometimes to a few ohms, which depends on the intensity of light. LDR's sensitivity depends and varies with the wavelengths of applied light and are also nonlinear devices.

\section{WORKING}

The solar panel collects the sun light and generates energy which is stored in a re-chargeable battery. The wind turbine also generates energy and stores in a re-chargeable battery in the form of dc power. The DC power is now converted into ac power with the help of inverter since the water pump motor works with ac power. The regulated power supply is used to attain required voltage that is required for the circuit to run. This circuit can work either in day time or in night time or both.

The use of comparator here is used for detecting. The comparator is used along with LDR. Since the LDR works based on the light intensity during night LDR has low resistance and the water pumping system will be working in the night which is done by converting the energy that is stored in a $12 \mathrm{v}$ battery since morning. If we want to run the system whole day, the comparator can be deduced because the LDR has high resistance during day time. The energy in the battery which is in the form of DC is inverted with the help of inverter into $\mathrm{AC}$ and is step-up to the required voltage by the motor by step-up transformer.

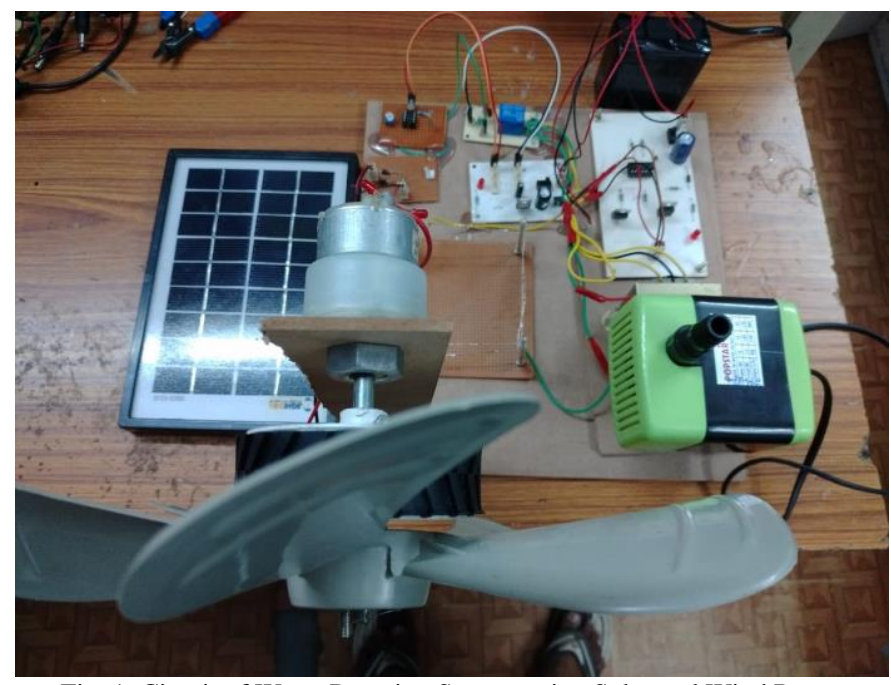

Fig. 1: Circuit of Water Pumping System using Solar and Wind Power 


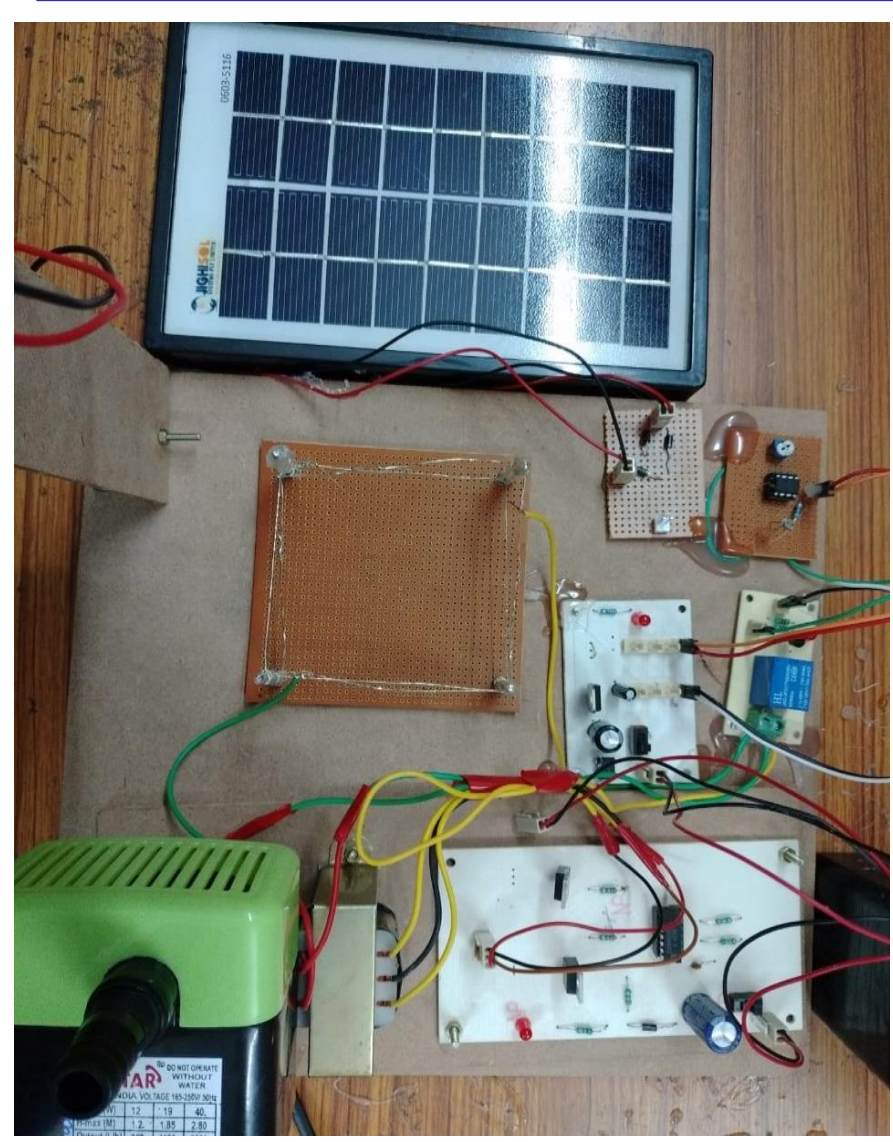

Fig. 2: Circuit of Water Pumping System using Solar and Wind Power

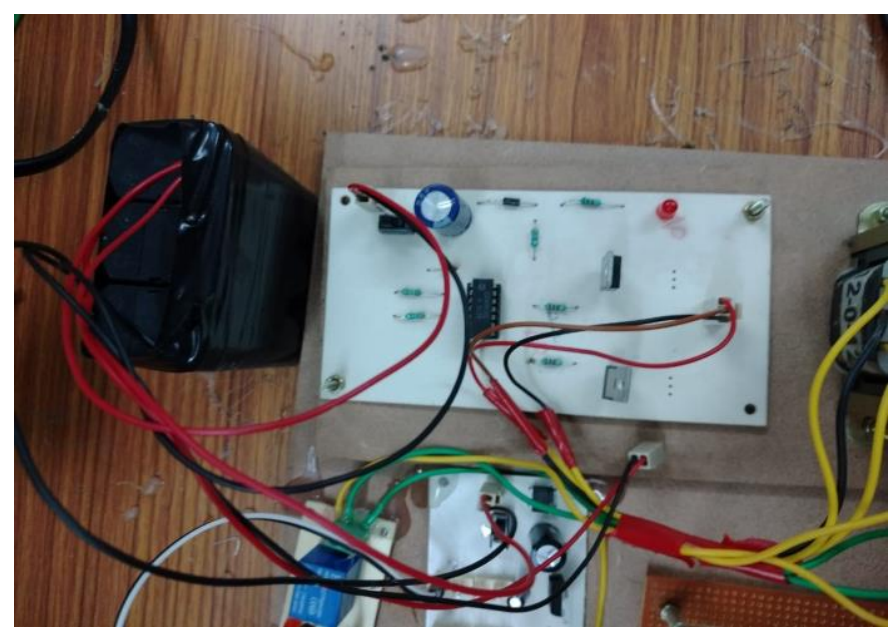

Fig. 3: Inverter Circuit

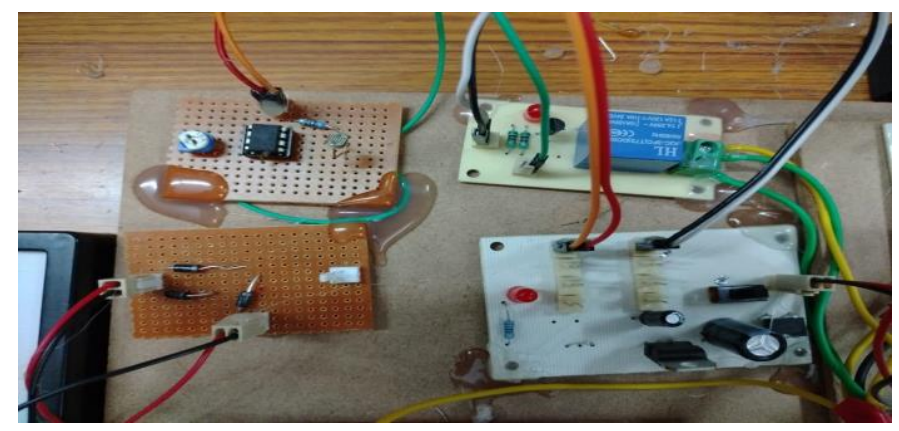

Fig. 3: Voltage Regulator, Comparator, Relay and RPS Circuit

\section{RESULT}

By using this project we can design a "Water pumping system using solar and wind power" and can be successfully developed. This project proposed the design and architecture of a new concept of electricity available. The advantage of the system lies in the fact that it helps to pump water even when there is availability of electricity.

\section{CONCLUSION}

The wind turbine generates variable output power and hence, it cannot be matched with the PV module in normal cases. But in this hybrid system this problem is overcome by connecting the solar module and the wind turbine to the utility pumping system. It only uses the renewable sources of energy, thus forming a standalone hybrid system. Even after installation of this system, if required additional sensors can also be interfaced with the arduino controller, leading to efficient functioning of the system.

\section{ACKNOWLEDGEMENT}

We are thankful to our principal Dr. G. DURGA SUKUMAR for giving us permission to carry out this project. We acknowledge Dr. T RAMA SUBBA REDDY, Head of Department of Electrical \& Electronic Engineering for his guidance and moral support throughout the project.

We extend our sincere thanks to Mr. SRIKANTH D, Assistant Professor Electrical \& Electronics Engineering for his guidance and valuable suggestions, bondless co-operation, and encouragement throughout the project.

Lastly, we also extend our thanks to all the staff of the Department of Electrical \& Electronics Engineering, VITS for their co-operation and support during our course work.

\section{REFERENCES}

[1] Wind Power Plants: Fundamentals, Design, Construction and Operation, R. Gasch, J. Twele, et al., Springer Verlag, 2012

[2] Performance Test on Helical Savonius Rotor, S.B. Kedare, 2003.

[3] Wind Power Fundamentals: Alex Kalmikov and Katherine Dykes With contributions from: Kathy Araujo PhD Candidates, MIT Mechanical Engineering, Engineering Systems and Urban Planning MIT Wind Energy Group \&Renewable Energy Projects in Action.

[4] Hybrid-solar and wind mill operated water pump Prathamesh d. Dalvi, dheeraj p. Dhokale, dhiraj b. Gondkar, rajat r. Kadam, ayub.a.tamboli.

[5] Raturi,A., Feasibility study of a solar water pumping system ,Appl. Sol. Energy,2011,vol. 47, no.1,pp.11-13.

[6] Chikh, A., and Chnadra, A., Optimization and control of a photovoltaic powered water pumping system, Conference on Power and Energy, 2009.

[7] Chenni R.,Zarour, L., Bouzid, A., and Kerbachet, T., Comparative study of photovoltaic pumping systems using a PMSM and ASM, Rev. Renewable Energy, 2006, vol.9, pp.17-28.

[8] Serir, C. and Rekioua, D., Control of Photovoltaic water pumping system, Russ. J. Electr. Eng., 2015, vol. 15,no.2, pp. 339-344.

[9] Khiareddine, A., Ben Salah, C., and Mimouni, M.F., Strategy of energy control in $\mathrm{PVP} / \mathrm{battery}$ water pumping system, First International Conference on Green Energy ICGE,2014.

[10] AlBadi, A. , Yousef, H. , AlMahmoudi, T. , AlShammaki, M. , AlAbri, A. ,\& Al-Hinai, A. (2018). Sizing and modelling of photovoltaic water pumping system. International Journal of Sustainable Energy , 37(5), 415-427. 